\title{
Sensory experience ratings for 5,500 Spanish words
}

\author{
Antonio M. Díez-Álamo ${ }^{1,2}$ [D $\cdot$ Emiliano Díez ${ }^{1} \cdot$ Dominika Zofia Wojcik $^{1} \cdot$ María Angeles Alonso $^{3} \cdot$ Angel Fernandez $^{1}$
}

Published online: 8 June 2018

(C) Psychonomic Society, Inc. 2018

\begin{abstract}
Sensory experience rating (SER) is a recently developed subjective lexical index that reflects the extent to which a word evokes a sensory and/or perceptual experience in a reader (Juhasz \& Yap, 2013; Juhasz, Yap, Dicke, Taylor, \& Gullick, 2011). In the present study, SERs for a set of 5,500 Spanish words were collected, which makes this the largest set of norms for SER in the Spanish language to date. Additionally, with the aim of further exploring the implications of this new indicator and its relations with other psycholinguistic variables, a variety of correlational and regression analyses are provided. The results showed that SERs significantly correlated with imageability, age of acquisition, and a number of variables related to perception and emotion. In addition, SERs predicted a significant amount of variance in lexical decision times when other variables were controlled.
\end{abstract}

Keywords Sensory experience ratings (SERs) $\cdot$ Spanish norms $\cdot$ Grounded cognition $\cdot$ Perception $\cdot$ Action $\cdot$ Emotion

Normative studies constitute highly valuable resources for researchers from different domains in cognitive science, since they allow for both manipulation and control in the design of experiments. In addition, these studies often give rise to new knowledge, thereby contributing to the enrichment of theoretical development in psychology. In the last decades, a large number of normative studies have been made available for several languages, mostly for English (see Proctor \& Vu, 1999, for a review; see also Vaughan, 2004), but also for other languages, such as Spanish (for a review, see Pérez, Campoy, \& Navalón, 2001), French (e.g., Bonin et al., 2003), Italian (e.g., Barca, Burani, \& Arduino, 2002), and Chinese (e.g., Liu, Shu, $\& \mathrm{Li}, 2007)$. Normative data have been collected for a variety of stimuli, among which verbal materials, and particularly words,

Electronic supplementary material The online version of this article (https://doi.org/10.3758/s13428-018-1057-0) contains supplementary material, which is available to authorized users.

María Angeles Alonso

maalonso@ull.es

Antonio M. Díez-Álamo

antonio_diezalamo@usal.es

INICO, University of Salamanca, Salamanca, Spain

2 Facultad de Psicología, Universidad de Salamanca, Avda. de la Merced 109-131, 37005 Salamanca, Spain

3 Facultad de Psicología, Universidad de La Laguna, Campus de Guajara, 38205 La Laguna, Spain predominate over others. Also, numerous psycholinguistic variables, both objective (e.g., number of letters/syllables, word frequency, orthographic, and phonological structure) and subjective (e.g., familiarity, imageability, concreteness, affective values, age of acquisition), have been carefully studied. As a result, an extensive corpus of word ratings is available today, which constitutes a major advantage for researchers.

In recent times, new theoretical points of view in cognitive psychology have led to growing interest in new variables. In this sense, a remarkable perspective in psychology, which has aroused great interest among researchers, is the grounded cognition theoretical framework, which holds that cognition is determined, in multiple ways, by modality-specific simulations, bodily states, and situated action, within a physical and social context (Barsalou, 2008). Thus, all psychological processes and mental activities would be influenced in a significant way by sensorimotor systems, emotions, and the body itself (Glenberg, 2011). For instance, recent studies suggest that language comprehension implies constructing sensorimotor simulations of the situations and events described in sentences. According to this perspective, those simulations involve the activation of the brain's systems of perception, action, and emotion, the same ones that are activated in a real situation (Glenberg, 2011; Glenberg \& Kaschak, 2002; Kaschak et al., 2005). In a similar vein, conceptual representations, and therefore our knowledge about the world, have been argued to be grounded in modality-specific systems (Barsalou, Simmons, Barbey, \& Wilson, 2003; Kiefer \& Barsalou, 2013). More specifically, Barsalou (1999) 
suggested that perceptual states that emerge from sensorimotor systems are stored in long-term memory and can operate as symbols that are modal and analogical in nature.

Due to the considerable interest that this approach has elicited among a good number of researchers, and owing to the importance that sensory systems certainly have for understanding human cognition, it becomes necessary to collect information about sensory properties of concepts, as completely and rigorously as possible. This will allow researchers to conduct further investigation with carefully selected materials and with appropriate control of variables. In this context, Juhasz, Yap, Dicke, Taylor, and Gullick (2011; see also Juhasz \& Yap, 2013) were first to present a new variable called sensory experience rating (SER), which reflects the extent to which a word evokes a sensory and/or perceptual experience in the reader. As Juhasz et al. (2011) stated in the original instructions of the task, this sensory experience implies an actual sensation (taste, touch, sight, sound, or smell) that is experienced when a certain word is read. It is noticeable that the SER index is not referred to a single sensorial modality, but it examines all sensations at one time. In that respect, SER is different from other indexes that have focused on individual sensorial modalities. For example, Lynott and Connell (2013) provided modality-specific norms for 400 nouns, including ratings for each of the five sensorial modalities (i.e., auditory, gustatory, haptic, olfactory, and visual). Similarly, Medler, Arnoldussen, Binder, and Seidenberg (2005) collected ratings in four sensorimotor domains (sound, color, manipulation, and motion), as well as emotion ratings, for 1,402 English words. And McRae, Cree, Seidenberg, and McNorgan (2005) collected semantic feature production norms for 541 living (e.g., dog) and nonliving (e.g., chair) concepts, which were then grouped into nine knowledge types, among which the five sensorial modalities are included. Furthermore, Amsel, Urbach, and Kutas (2012) provided ratings for a set of 559 object concepts on seven different perceptual and motor attributes (color, motion, sound, smell, taste, graspability, and pain). Interestingly, these norms include some attributes that, to date, have received little attention in conceptual processing studies, such as smell intensity or likelihood of pain. Another variable that addresses the importance of sensorimotor representations in cognition is the body-object interaction (BOI) index, which reflects the ease with which individuals can physically interact with a word's referent using any part of their body (Bennett, Burnett, Siakaluk, \& Pexman, 2011; Tillotson, Siakaluk, \& Pexman, 2008). SER, as an integrative measure of the sensory activation that concepts evoke, should encapsulate all individual sensorial modalities and should correlate with different subjective variables that tap perception, action and emotion in different ways. In this vein, one of the main purposes of the present study is precisely to explore these relations.

Furthermore, recent studies have explored how SER is related to semantic or lexical psycholinguistic variables as well as to performance measures of word recognition. Thus, the most remarkable correlations have been reported between SER and imageability and age of acquisition (AoA), indicating that words with higher SERs are more likely to be more imageable and to have an earlier AoA in comparison with low-SER words (Bonin, Méot, Ferrand, \& Bugaïska, 2015; Juhasz, Lai, \& Woodcock, 2015; Juhasz \& Yap, 2013; Juhasz et al., 2011). Also, a recent study by Bonin, Méot, and Bugaiska (2018) has found a positive correlation between concreteness and SER ratings, indicating that words with higher SERs tend to be more concrete. These researchers argue that, similarly to high-SER words, the representation of concrete words might be mainly based on sensory-perceptual information (see also Kousta, Vigliocco, Vinson, Andrews, \& Del Campo, 2011). However, despite the mentioned correlations, SER has been argued to have a unique character as a semantic variable. For example, Juhasz et al. (2011) reported a multiple regression analysis with SER as the dependent variable, in which a total of ten established word recognition variables only predicted $29.4 \%$ of the variance in SER. Moreover, and importantly, SERs have proved to reliably predict lexical decision response times (Bonin et al., 2015; Juhasz et al., 2015; Juhasz \& Yap, 2013; Juhasz et al., 2011; Kuperman, 2013) when other psycholinguistic variables are controlled, suggesting that it plays a significant role in conceptual lexical-semantic processing, particularly when sensory and perceptual features of concepts are taken into account.

Given the growing interest in this new variable and its potential importance for several research aims in cognitive psychology, SERs started to be collected in languages other than English. For example, Bonin et al. (2015) recently obtained SERs for 1,659 French words. In Spanish, Hinojosa, Rincón-Pérez, et al. (2016b) collected SERs for the 875 words included in the Madrid Affective Database for Spanish (MADS; Hinojosa, Martínez-García, et al., 2016a), including verbs, nouns and adjectives. To the best of our knowledge, this is the only normative SER study in Spanish.

With the aim of further contributing to this growing body of data, the present study's main objective was to provide SERs for a set of 5,500 Spanish words. Importantly, the target words were selected from previous studies collecting Spanish norms for other relevant psycholinguistic variables, so that researchers using verbal stimuli in Spanish can make use of a rich and well-described pool of words for experimental purposes. A second objective was to analyze the relationships between SER and other well-established psycholinguistic objective and subjective indexes, in order to further explore and describe the implications of this variable for information processing. AoA, frequency and imageability are of particular interest here, as these variables have been found to correlate with the SER. Also, because it is argued that SER is a unique semantic variable that encloses diverse individual sensorial modalities that underpin perception, action, and emotion, the 
relationship between SER and different subjective psycholinguistic variables associated with those three dimensions will be examined. And finally, as it was done in previous studies in English and French, the predictive value of the SER on Spanish language lexical decision times and word naming will be assessed.

\section{Method}

\section{Participants}

A total of 420 undergraduate students of the Universities of Salamanca, Valladolid, and La Laguna, all located in Spain, participated in the study in exchange for course credit. All data from 29 participants were discarded due to inadequate performance in the rating task, applying at least one of two criteria: 20 or more trials in a row with the same response, or 50 or more responses made in less than one second. Thus, the final sample included 391 participants (333 female, 58 male), all native speakers of Spanish, with a mean age of 19.7 years $(S D$ $=3.23$; range $=16-58$ years) .

\section{Stimuli}

The set of words to be normed was constructed by obtaining stimuli from existing lexical databases in Spanish, with the aim of assembling a pool of words for which other norms of psycholinguistic interest were currently available. Specifically, the set was formed to include (a) 2,765 monoand multisyllabic words with known lexical-decision and word-naming times (Davies, Barbón, \& Cuetos, 2013; González-Nosti, Barbón, Rodríguez-Ferreiro, \& Cuetos, 2014); (b) 1,512 words with known affective norms (Redondo, Fraga, Comesaña, \& Perea, 2005; Redondo, Fraga, Padrón, \& Comesaña, 2007); (c) 750 words with known BOI norms (Alonso, Díez, Díez-Álamo, \& Fernandez, 2018); (d) 238 one-word names denoting Snodgrass and Vanderwart's (1980) drawings (Fernandez, Díez, Alonso, \& Beato, 2004; Sanfeliu \& Fernandez, 1996); (e) the 1,109 adjectives with known AoA norms from Alonso, Fernandez, and Díez (2015); and (f) a subset of 1,024 verbs with known AoA norms from Alonso, Díez, and Fernandez (2016), representing the complete range of AoA (from 3 to 15). We also added six other nouns corresponding to months and days of the week, in order to complete those categories. Once redundant entries were eliminated, the final set was composed of a total of 5,500 Spanish words of varied length, frequency, and part-of-speech category (i.e., grammatical category).

\section{Procedure}

The 5,500 stimuli were randomly divided into 11 questionnaires, which were administered using Online Ratings of Visual Stimuli (OR-Vis), an open-source software tool (Hirschfeld, Bien, de Vries, Lüttmann, \& Schwall, 2010) developed to conduct rating studies. Each questionnaire contained 500 different words, as well as 23 repeated words, selected randomly from among the words within each questionnaire, that would allow for a subsequent intrasubject reliability test. Each target word was rated by an average of 35 participants, with a minimum of 33 valid observations for each word.

The task was performed in groups of 15 to 25 participants at a time, using individual computers in a large computer room. Each participant was randomly assigned to one of the questionnaires, with the only restriction that a similar proportion of male and female participants' responses were recorded across questionnaires. Participants were required to rate the 523 target words, which were randomly presented. In each trial, a target word was presented in the center of a computer screen and a 7-point rating scale was displayed below, with verbal labels at both extremes indicating the scale values. Participants had to rate the degree of sensory experience that each word evoked for them by selecting a single number on the scale, via mouse click. Participants were asked to answer quickly, but as accurately as possible.

The rating instructions were taken from Juhasz et al.'s (2011) seminal study. These instructions were translated into Spanish (see the exact instructions in the Appendix) and were displayed on the computer screen before the experimental trials. The duration of the experimental sessions was between 45 and $60 \mathrm{~min}$. Although no breaks were scheduled during the experimental session, participants were instructed to work at their own pace and allowed to take brief breaks between stimuli when needed.

\section{Results and discussion}

The complete set of SER ratings for the 5,500 stimuli are available for downloading from the journal website as supplementary materials (SpanishSER.xlsx). The file includes a column listing the 5,500 Spanish words in alphabetical order, with a matching column listing their English translations. In adjacent columns, the mean rating (SER $\mathrm{m}$ ) and the corresponding standard deviation (SER_sd) are provided for each word.

The distribution of the mean SERs was characterized by an average score of 3.63 , a standard deviation of 0.86 , a median of 3.57 , and a range of 5.07, with a minimum value of 1.47 and a maximum value of 6.54. As can be seen in Fig. 1, ratings were well distributed along the 7-point scale, with a skewness of $0.32(S E=0.03)$ and a kurtosis of $-0.35(S E=0.07)$. For completeness, descriptive statistics were calculated for the 


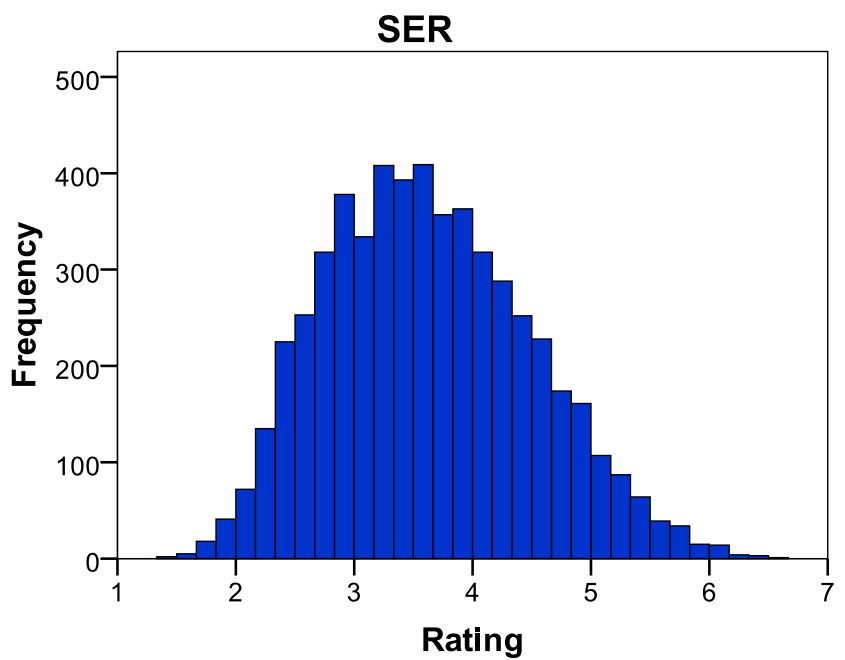

Fig. 1. Distribution of sensory experience ratings (SERs) for the 5,500 words

words in each part-of-speech category (i.e., word class/ grammatical category), which was extracted from the EsPal database $^{1}$ (Duchon, Perea, Sebastián-Gallés, Martí, \& Carreiras, 2013). Very small differences were found between the overall mean scores of the different categories. These data are presented in Table 1. Words pertaining to categories with less than 15 members in this study were grouped in a single category, under the name Other.

\section{Reliability and validity}

Prior to exploring SER's relationship with other variables, we established the reliability and validity of our study. To assess interrater reliability, the intraclass correlation (ICC) was calculated (two-way random consistency model, average measures) for each one of the 11 questionnaires. ICC values ranged from .89 to .92 , with a mean of .91 , indicating a good interrater reliability (Hallgren, 2012). Also, a mean Cronbach's alpha of .91 (with values ranging from .89 to .92) indicated good internal consistency. In addition, as mentioned above, each questionnaire contained 23 words that were presented twice, making a total of 253 repeated stimuli in the study ( 23 words $\times 11$ questionnaires), which allowed for analyzing intrasubject reliability. A high positive correlation $(r$ $=.969, p<.001)$ revealed very good intrasubject reliability.

The validity of the present norms was assessed in two ways. First, we translated our stimuli into English ${ }^{2}$ and compared the ratings with the norms provided by Juhasz and Yap (2013) for a set of 2,988 shared words. The correlation was

\footnotetext{
${ }^{1}$ The part-of-speech categories for four words that were not contained in EsPal, as well as their numbers of letters and syllables, were assigned by the first author.

${ }^{2}$ The 5,500 Spanish words were initially translated into English using Google Translate. In a second step, all the resulting translations were revised by two of the authors (A.M.D.-Á. and D.Z.W.), who are proficient in both Spanish and English.
}

Table 1. Descriptive statistics for the sensory experience ratings as a function of part-of-speech category (word class)

\begin{tabular}{llllll}
\hline Word Class & $N$ & Mean & $S D$ & Minimum & Maximum \\
\hline Total & 5,500 & 3.63 & 0.86 & 1.47 & 6.54 \\
Nouns & 2,689 & 3.62 & 0.90 & 1.47 & 6.37 \\
Adjectives & 1,169 & 3.68 & 0.81 & 1.68 & 6.11 \\
Verbs & 1,611 & 3.62 & 0.84 & 1.70 & 6.54 \\
Other & 31 & 3.55 & 0.80 & 2.18 & 5.49 \\
\hline
\end{tabular}

* Other = prepositions, adverbs, dates, determiners and interjections

positive and significant, although moderate $(r=.435, p<$ .001 ), probably due to the fact that different meanings exist for superficially equivalent words in the two languages, and other translation issues. However, in a second validity analysis we compared our results with the norms provided by Hinojosa, Rincón-Pérez, et al. (2016b), the only published study that has collected SER ratings in Spanish to date, and a correlation of $r=.818(p<.001)$ was found for a set of 471 shared words. Although translation issues are the most likely explanation for the difference between the correlations of our norms with those from the aforementioned SER studies in English and Spanish, cross-cultural differences in SER ratings should also be considered and explored in more detail in the future, since a few normative studies have found substantial differences in normative measures as a function of culture (e.g., Umla-Runge, Zimmer, Fu, \& Wang, 2012; Yoon et al., 2004).

\section{Relation to other psycholinguistic variables}

Pearson correlation analyses were carried out to explore the correlations between SER and objective and subjective lexical descriptors, obtained from different available sources (see Table 2). The correlations between SER and several objective variables - such as log written frequency, number of letters, number of syllables, number of homophones, number of orthographical neighbors, and number of phonological neighbors (extracted from the EsPal database; Duchon et al., 2013) - were low. However, and interestingly in terms of language processing, a moderate negative correlation $(r=-.331$, $p<.001$ ) was found between SERs and lexical decision times (from González-Nosti et al., 2014; shared $n=2,765$ ), in that words with higher SER tended to be processed faster. This finding replicates the results obtained in previous SER studies in other languages (Bonin et al., 2015; Juhasz \& Yap, 2013; Juhasz et al., 2011). In contrast, the correlation between SER and word-naming latencies (from Davies et al., 2013; shared $n$ $=2,764)$, although significant, was very weak $(r=.060, p=$ .002 ), and hence does not allow us to draw firm conclusions on the relationship between these two variables.

As a way to further explore the role of SER in word recognition performance, two four-step hierarchical linear regression 
Table 2. Correlations between sensory experience ratings and other objective and subjective variables

\begin{tabular}{|c|c|c|c|c|}
\hline Variable & Study & $r$ & $p$ & $N$ \\
\hline Lexical decision times & González-Nosti et al. (2014) & -.331 & $<.001$ & 2,765 \\
\hline Naming times & Davies et al. (2013) & .060 & .002 & 2,764 \\
\hline Semantic neighborhood density & Fernandez et al. (2017), Fernandez et al. (2004) & .096 & $<.001$ & 3,452 \\
\hline Number of letters & Duchon et al. (2013) & -.079 & $<.001$ & 5,500 \\
\hline Number of syllables & & -.057 & $<.001$ & 5,500 \\
\hline Number of homophones & & -.001 & .968 & 5,496 \\
\hline Number of orthographical neighbors & & .006 & .639 & 5,496 \\
\hline Number of phonological neighbors & & .005 & .702 & 5,496 \\
\hline Phonological uniqueness point & & -.085 & $<.001$ & 5,496 \\
\hline Orthographic uniqueness point & & -.082 & $<.001$ & 5,496 \\
\hline Levenshtein distance & & -.037 & .006 & 5,496 \\
\hline Familiarity & & .381 & $<.001$ & 3,463 \\
\hline Concreteness & & .169 & $<.001$ & 3,465 \\
\hline Imageability & & .321 & $<.001$ & 3,383 \\
\hline Log written frequency & & .067 & $<.001$ & 5,496 \\
\hline Oral frequency & Alonso et al. (2011) & .128 & $<.001$ & 4,998 \\
\hline AoA & Alonso et al. (2016); Alonso et al. (2015) & -.376 & $<.001$ & 4,911 \\
\hline
\end{tabular}

analyses were performed, with lexical decision and wordnaming response times (RTs) as dependent variables, and a set of common predictor variables entered in successive steps, before adding SERs in the last step. Specifically, in Step 1, several lexical variables were entered: 11 initial phoneme features (vowel, alveolar, palatal, velar, bilabial, dental, voiced, occlusive, nasal, fricative, and liquid), coded as 0 or 1 for each feature (obtained from Davies et al., 2013), and also six variables related to the lexical-word-form level — namely, number of letters, number of syllables, orthographic neighborhood size, phonological neighborhood size, log written frequency (from EsPal; Duchon et al., 2013), and oral word frequency (from Alonso, Fernandez, \& Díez, 2011). In Step 2, a measure of the objective semantic properties of the words was entered - namely, semantic neighborhood density (see Mirman \& Magnuson, 2006), based on the number of nonidiosyncratic associates with a frequency of production of $>1$ for the word, taken from a large Spanish freeassociation database (Fernandez, Díez, \& Alonso, 2017; Fernandez et al., 2004). In Step 3, two subjective measures thought to be related to semantic processing were included, namely imageability (from EsPal; Duchon et al., 2013) and AoA (from Alonso et al., 2016; Alonso et al., 2015). Finally, following the procedure of Juhasz and Yap (2013), SERs were entered in the final step of both analyses. As is shown in Table 3, the amount of change in the variance predicted by SERs was low but significant for lexical decision times $\left(\Delta R^{2}=.013\right)$ and nonsignificant for naming times. The same pattern of results was obtained by Juhasz et al. (2011) and Bonin et al. (2015). In contrast, Juhasz and Yap (2013) found that SER predicted a reliable, although small, amount of variance in both lexical decision and naming response times. The fact that SER and other semantic variables did not significantly predict naming RTs in the present study, as compared with the results obtained by Juhasz and Yap, could be attributed to a very particular linguistic characteristic. Specifically, Spanish, like Italian or Finnish, but unlike languages such as English, has a very transparent orthography, and any word can be correctly named by applying basic pronunciation rules, making semantic access unnecessary in naming most of the words, or allowing for a

Table 3. Proportions of variation (adjusted $R^{2}$ ) in lexical decision and naming response times (RTs), explained by several predictor variables (hierarchical linear regression analyses)

\begin{tabular}{lll}
\hline Predictor Variable & $\begin{array}{l}\text { Lexical Decision RTs } \\
(n=1,758)\end{array}$ & $\begin{array}{l}\text { Naming RTs } \\
(n=1,758)\end{array}$ \\
\hline
\end{tabular}

Step 1: Lexical variables

$\begin{array}{lll}\text { Adjusted } R^{2} & .387 & .013 \\ \text { Change in } R^{2} & .393^{\text {**** }} & .023^{\text {*** }}\end{array}$

Step 2: Objective semantic variables

$\begin{array}{lll}\text { Adjusted } R^{2} & .400 & .013 \\ \text { Change in } R^{2} & .014^{* * * *} & .0001\end{array}$

Step 3: Subjective semantic variables

$\begin{array}{lll}\text { Adjusted } R^{2} & .510 & .013 \\ \text { Change in } R^{2} & .11^{* * * *} & .0009\end{array}$

Step 4: Sensory experience ratings

$\begin{array}{lll}\text { Adjusted } R^{2} & .523 & .0126 \\ \text { Change in } R^{2} & .013^{* * * *} & .0004\end{array}$

${ }^{* *} p<.01{ }^{* * * *} p<.001$ 
combination of lexical and sublexical processes (Kwok, Cuetos, Avdyli, \& Ellis, 2017).

Besides the correlations described above, moderate correlations were found between SER and other subjective variables of common use in psycholinguistics. For instance, SER correlated positively with imageability $(r=.321, p<$ .001) (from EsPal; Duchon et al., 2013; shared $n=3,383$ ), and negatively with AoA $(r=-.376, p<.001)$ (obtained from Alonso et al., 2016; Alonso et al., 2015; shared $n=4,911){ }^{3}$ Thus, words with higher SERs tend to be more imageable and to be acquired earlier than low-SER words. These results replicate the most notable pattern of correlations with subjective indexes found in previous English and French SER studies (Bonin et al., 2015; Juhasz et al., 2015; Juhasz \& Yap, 2013; Juhasz et al., 2011). Importantly, the relation between SER and AoA supports the idea that concepts acquired earlier in life tend to be associated with sensory-perceptual experiences (Juhasz \& Yap, 2013), and it is in line with groundedcognition approaches claiming that sensorimotor experiences are essential to reaching a comprehensive understanding of what AoA represents (Thill \& Twomey, 2016). Furthermore, SER also correlated positively with familiarity (from EsPal; Duchon et al., 2013; shared $n=3,463)(r=.381, p<.001)$, which is consistent with Juhasz et al.'s (2015) results, indicating that words that evoke a greater sensory experience tend to be more familiar. In this sense, it also seems that high-SER words tend to be more frequent in spoken language, as reflected by the correlation between SER and oral frequency $(r=.128, p<.001)$ (from Alonso et al., 2011; shared $n=$ 4,998). The correlation with $\log$ written frequency (from EsPal; Duchon et al., 2013; shared $n=5,496$ ), though, was lower $(r=.067, p<.001)$. Additionally, in line with the correlations reported by Hinojosa, Rincón-Pérez, et al. (2016b) and Bonin et al. (2018), concreteness (from EsPal; Duchon et al., 2013; shared $n=3,465)$ correlated positively with SER $(r=.169, p<.001)$, suggesting that words that imply a high sensory experience also tend to denote more concrete concepts.

\section{Relation to perception, action and emotion variables}

It has been argued that SER is an integrative semantic variable that encloses diverse individual sensorial modalities that underpin perception, action, and emotion. To study the relationship between SER and those three dimensions, correlational analyses were conducted between SER and different subjective psycholinguistic variables associated with perception, action, and emotion in different ways. Table 4 presents a tentative organization of relevant subjective variables into these three domains, as well as the correlation with SER in each case. Most variables had

\footnotetext{
$\overline{3}$ In the cases that a word was present in both studies, the average of the two numbers was used.
}

significant correlations with SERs, with larger values being observed for perceptual attributes such as color, taste, or smell, and for emotional values such as happiness or fear.

With the aim of studying in more detail the relationship between SER and individual perceptual-sensorial modalities, we examined the correlations between SER and subjective ratings for seven different perceptual and motor attributes of object concepts - namely, color vividness, visual motion, sound intensity, smell intensity, taste pleasantness, graspability, and likelihood of pain (from Díez-Álamo, Díez, Alonso, Vargas, \& Fernandez, 2017; shared $n=506$ ), dimensions that engage the five Aristotelian sensory modalities (vision, touch, hearing, smell, and taste), in addition to a related sense, namely the likelihood that an object will cause pain. The highest values corresponded to positive correlations between SER and color vividness $(r=.419, p<.001)$, taste pleasantness $(r=.355, p<.001)$, and smell intensity $(r=$ $.296, p<.001)$, reflecting that high-SER words tend to elicit higher ratings particularly in these three dimensions. Interestingly, these three variables formed a statistically determined cluster in studies by Amsel et al. (2012) and by DíezÁlamo et al. (2017), as shown by principal component analyses (PCAs) and supported by the patterns of intercorrelations among the seven attributes. In both studies, the cluster was interpreted as a factor related to survival, described as "locating nourishment," and included mostly objects with vivid colors, good taste, and a strong smell (mostly foods). Thus, the SER variable may be connected, to a large extent, to knowledge types that are most notable in the conceptual representations of edible things (Amsel et al., 2012). It should be kept in mind, though, that the studies by Amsel et al. and Díez-Álamo et al. only included nouns denoting object concepts, so further exploration will be needed to examine the relationship between SER and the sensory modalities for words representing other grammatical categories.

In terms of action, two different subjective variables were taken into consideration. The first of these was graspability (the likelihood that an object can be grasped by someone with a hand, as reported in Díez-Álamo et al., 2017), which besides being related to the sense of touch is also regarded as an actionrelated dimension. However, the correlation between SER and graspability was not significant $(r=-.071, p=.113)$. The other examined action variable was the body-object interaction (BOI) index, which reflects the ease with which individuals can physically interact with an object using any part of their body (Bennett et al., 2011; Tillotson et al., 2008). Again, there was no relationship between BOI ratings (reported in Alonso et al., 2018; shared $n=750)$ and SER ( $r=-.007, p=.846)$. It seems, therefore, that SER does not show a clear association with action variables, in contrast to its more obvious relationship with variables that address perceptual dimensions.

Two different but complementary approaches have been used to study emotion and affective language. One approach 
Table 4. Correlations between sensory experience ratings and subjective variables related to perception, action, and emotion

\begin{tabular}{|c|c|c|c|c|c|}
\hline Dimension & Variable & Study & $r$ & $p$ & $N$ \\
\hline \multirow[t]{6}{*}{ Perception } & Color & \multirow[t]{6}{*}{ Díez-Álamo et al. (2017) } & .419 & $<.001$ & 506 \\
\hline & Pain & & .098 & .027 & 506 \\
\hline & Sound & & .149 & .001 & 506 \\
\hline & Taste & & .355 & $<.001$ & 506 \\
\hline & Smell & & .296 & $<.001$ & 506 \\
\hline & Visual motion & & .183 & $<.001$ & 506 \\
\hline \multirow[t]{2}{*}{ Action } & Graspability & Díez-Álamo et al. (2017) & -.071 & .113 & 506 \\
\hline & BOI & Alonso et al. (2018) & -.007 & .846 & 750 \\
\hline \multirow[t]{7}{*}{ Emotion } & Happiness & \multirow{5}{*}{$\begin{array}{l}\text { Ferré et al. (2017); Hinojosa, Martínez-García, et al. (2016a); } \\
\text { Stadthagen-González, Ferré, et al. (2017a) }\end{array}$} & .361 & $<.001$ & 4,498 \\
\hline & Disgust & & .117 & $<.001$ & 4,498 \\
\hline & Anger & & .157 & $<.001$ & 4,498 \\
\hline & Fear & & .290 & $<.001$ & 4,498 \\
\hline & Sadness & & .249 & $<.001$ & 4,498 \\
\hline & Valence & \multirow[t]{2}{*}{ Stadthagen-González, Imbault, et al. (2017b) } & .105 & $<.001$ & 4,421 \\
\hline & Arousal & & .254 & $<.001$ & 4,421 \\
\hline
\end{tabular}

is that of dimensional models, which conceptualize all human emotions as being based on three underlying affective dimensions: valence (ranging from pleasant to unpleasant), arousal (ranging from calm to excited), and dominance or control (ranging from out of control to in control) (Bradley \& Lang, 1999). The dominance dimension has been shown to be less consistent across languages than valence (Redondo et al., 2007; Warriner, Kuperman, \& Brysbaert, 2013), a weaker predictor of variance than valence and arousal (Bradley \& Lang, 1994), and to be highly correlated with valence (Warriner et al., 2013). As a result, most modern studies in a variety of domains (such as language, memory, and emotion) usually do not include dominance in their models (e.g., Ferré, Guasch, Moldovan, \& Sánchez-Casas, 2012; Kensinger \& Corkin, 2004; Kuperman, Estes, Brysbaert, \& Warriner, 2014; Stadthagen-González, Imbault, Pérez Sánchez, \& Brysbaert, 2017b). Thus, for the purpose of this study, we also decided to focus on the valence and arousal dimensions. As we explained in the Method section, we initially selected 1,512 words with known affective norms from Redondo et al. (2005, 2007). However, during the final stages in the preparation of the present report, a much larger normative study with norms of valence and arousal was published (StadthagenGonzález, Imbault, et al., 2017b), including all the words in Redondo et al. (2007) and over $95 \%$ of the words in Redondo et al. (2005). Consequently, to maximize the number of shared items with our study, we decided to use the norms provided by Stadhagen-González, Imbault, et al. to calculate the correlations between our SER ratings and valence and arousal for a total of 4,421 shared words. A positive significant correlation was found between SER and valence $(r=.105, p<.001)$, reflecting a tendency for high-SER words to be judged as more positive. A larger positive correlation was found between SER and arousal $(r=.254, p<.001)$, indicating that, as was previously found by Hinojosa, Rincón-Pérez, et al. (2016b), words with higher SERs were more likely to be judged as being relatively more arousing than words with lower SERs.

An alternative approach for studying emotion, supported by research in facial expressions (Ekman, 1993, 1999), is based on the existence of a limited number of discrete basic emotions. Although there is no complete consensus regarding the number of discrete basic emotions, five of them (happiness, disgust, anger, fear, and sadness) have received stronger support (Oatley \& Johnson-Laird, 1987; Power \& Dalgleish, 1997). To further explore the role of SER in the emotional domain, we examined the correlations between SER and those five discrete emotions, using subjective emotional ratings for a set of 4,498 shared items obtained from a combination of three normative studies (Ferré, Guasch, Martínez-García, Fraga, \& Hinojosa, 2017; Hinojosa, Martínez-García, et al., 2016a; Stadthagen-González, Ferré, Pérez-Sánchez, Imbault, \& Hinojosa, 2017a). SER correlated significantly with the five discrete emotions, and all the correlations were positive (see Table 4). This is consistent with the results observed in Hinojosa, Rincón-Pérez, et al.'s (2016b) study. The highest correlation was found between SER and happiness $(r=.361$, $p<.001)$, indicating that words with a higher SER tend to denote more pleasant concepts.

\section{Additional regression analyses}

Finally, to explore more deeply the nature of SER ratings, two hierarchical regression analyses were conducted with SER as 
Table 5. Proportions of variation (adjusted $R^{2}$ ) in sensory experience ratings (SERs) explained by several predictor variables (hierarchical linear regression analyses)

\begin{tabular}{lll}
\hline Predictor Variable & $\begin{array}{l}\text { SER } \\
(n=2,272)\end{array}$ & $\begin{array}{l}\text { SER } \\
(n=318)\end{array}$ \\
\hline Step 1: Lexical variables & \\
$\quad$ Adjusted $R^{2}$ & .04 & .032 \\
Change in $R^{2}$ & $.043^{* * *}$ & $.05^{*}$ \\
Step 2: Objective semantic variables & .062 \\
Adjusted $R^{2}$ & .047 & $.033^{* * *}$ \\
Change in $R^{2}$ & $.007^{* * *}$ & \\
Step 3: Subjective semantic variables & .150 \\
Adjusted $R^{2}$ & .113 & $.09^{* * *}$ \\
Change in $R^{2}$ & $.066^{* * *}$ & \\
Step 4: Perception variables & & .324 \\
Adjusted $R^{2}$ & & $.18^{* * *}$ \\
Change in $R^{2}$ & \\
Step 5: Action variables & & .371 \\
Adjusted $R^{2}$ & $.05^{* * *}$ \\
Change in $R^{2}$ & \\
Step 6: Emotion variables & & .594 \\
Adjusted $R^{2}$ & & $.22^{* * *}$ \\
Change in $R^{2}$ & \\
\hline
\end{tabular}

${ }^{*} p<.05{ }^{* * * *} p<.001$

the dependent variable. The first analysis included the objective and subjective lexical and semantic variables used in the previously described regression analyses on lexical decision and naming times as successive predictors of SER ratingsexcluding the 11 initial phoneme features-for the set of 2,272 words that had all the scores available. A second analysis also included the perception, action, and emotion variables (listed in Table 4) in successive steps, but in this case for a reduced set of 318 words, since not all scores were available for the normed words. Table 5 shows the results of both analyses. Importantly, the nine lexical and semantic predictor variables only accounted for $11.3 \%$ of the variance in SERs (15\% in the reduced-set analysis), with the entering of subjective semantic variables in the model producing the greater increment in the explained variance. However, the greatest increments of explained variance were produced by entering perception $\left(\Delta R^{2}=.18\right)$, action $\left(\Delta R^{2}=.05\right)$, and emotional $\left(\Delta R^{2}=.22\right)$ variables, which together raised $R^{2}$ up to .59 .

\section{Conclusion}

In the present study, we provide SERs for a set of 5,500 Spanish words, which constitutes, to date, the largest set of norms for SER in Spanish language. Reliability and validity analyses showed that the norms provide adequate estimators of SER for this large set of words. In addition, with the exception of four entries, all of the words from the present study are contained in the EsPal database (Duchon et al., 2013). As a result, a very large amount of lexical information is available for all the words, including lemma information, word written frequency, and orthographic and phonological characteristics, as well as different subjective ratings for a subset of over 3,300 words. Additionally, almost 5,000 of the words are also described in oral frequency norms (Alonso et al., 2011), and AoA norms (Alonso et al., 2016; Alonso et al., 2015), and over 4,400 of the words are present in affective norms databases, including valence and arousal norms (Stadthagen-González, Imbault, et al., 2017b) and ratings for five discrete emotions (Ferré et al., 2017; Hinojosa, Martínez-García, et al., 2016a; Stadthagen-González, Ferré, et al., 2017a). Finally, lexical decision (González-Nosti et al., 2014) and naming response times (Davies et al., 2013) are available for approximately half of the words, and additional indexes of psycholinguistic interest can be found for smaller subsets of words. From a methodological point of view, the availability of SERs for a large set of words that are well characterized in many other dimensions has the potential to be of use to researchers interested in designing studies of conceptual representation, semantic memory, processing of affective language and other related issues with samples of Spanish-speaking participants. The norms also have the potential to be useful in studies on different aspects of bilingualism, and they might provide indications for future research efforts on cross-cultural issues. And from a broader theoretical perspective, our results are important for understanding the nature of the construct captured by SERs. Finally, the materials and the information about the relation between SER and other variables might be helpful for the strengthening and development of new lines of research in psychology, especially recent brain-inspired proposals about conceptual representation and conceptual processing that consider the need to integrate perceptual, motor and emotional information (e.g., Binder et al., 2016; Glenberg, 2015; Kiefer \& Barsalou, 2013; Lambon Ralph, Jefferies, Patterson, \& Rogers, 2017).

Author note The authors were supported by research grants awarded by the Spanish Ministry of Economy and Competitiveness (Grants PSI201342872-P and PSI2017-82748-P). Additional support came from a predoctoral grant from the University of Salamanca and Banco Santander to A.M.D.-Á. (Grant 463A.B.01, 2013), and from a research grant from Plan Propio de Investigación de la Universidad de La Laguna to M.A.A. (Grant 2017/0001035). The raw data from this study are available at the Open Science Framework (https://osf.io/52fah/). 


\section{Appendix: Rating instructions}

“A continuación se te presentará una serie larga de palabras. Por favor, lee y considera cada palabra basándote en el grado de experiencia sensorial que cada una evoca en ti. Por experiencia sensorial, entendemos una sensación real (gusto, tacto, vista, sonido, u olfato) que experimentas al leer la palabra. Por favor, evalúa cada palabra en una escala del 1 al 7 , donde 1 significa que la palabra no evoca ninguna experiencia sensorial en ti, 4 significa que la palabra evoca una experiencia sensorial moderada, y 7 significa que la palabra evoca una experiencia sensorial fuerte. No hay respuestas correctas o incorrectas. Estamos interesados en tu experiencia sensorial personal con estas palabras. Puedes indicar tu respuesta para cada palabra señalando el número que elijas en la escala."

\section{References}

Alonso, M. A., Díez, E., Díez-Álamo, A. M., \& Fernandez, A. (2018). Body-object interaction ratings for 750 Spanish words. Applied Psycholinguistics.

Alonso, M. A., Díez, E., \& Fernandez, A. (2016). Subjective age-ofacquisition norms for 4,640 verbs in Spanish. Behavior Research Methods, 48, 1337-1342. https://doi.org/10.3758/s13428-0150675-Z

Alonso, M. A., Fernandez, A., \& Díez, E. (2011). Oral frequency norms for 67,979 Spanish words. Behavior Research Methods, 43, 449458. https://doi.org/10.3758/s13428-011-0062-3

Alonso, M. A., Fernandez, A., \& Díez, E. (2015). Subjective age-ofacquisition norms for 7,039 Spanish words. Behavior Research Methods, 47, 268-274. https://doi.org/10.3758/s13428-014-0454-2

Amsel, B. D., Urbach, T. P., \& Kutas, M. (2012). Perceptual and motor attribute ratings for 559 object concepts. Behavior Research Methods, 44, 1028-1041. https://doi.org/10.3758/s13428-0120215-Z

Barca, L., Burani, C., \& Arduino, L. S. (2002). Word naming times and psycholinguistic norms for Italian nouns. Behavior Research Methods, Instruments, \& Computers, 34, 424-434. https://doi.org/ 10.3758/BF03195471

Barsalou, L. W. (1999). Perceptual symbol systems. Behavioral and Brain Sciences, 22, 577-660. https://doi.org/10.1017/ S0140525X99532147

Barsalou, L. W. (2008). Grounded cognition. Annual Review of Psychology, 59, 617-645. https://doi.org/10.1146/annurev.psych. 59.103006 .093639

Barsalou, L. W., Simmons, W. K., Barbey, A. K., \& Wilson, C. D. (2003). Grounding conceptual knowledge in modality-specific systems. Trends in Cognitive Sciences, 7, 84-91. https://doi.org/10.1016/ S1364-6613(02)00029-3

Bennett, S. D. R., Burnett, A. N., Siakaluk, P. D., \& Pexman, P. M. (2011). Imageability and body-object interaction ratings for 599 multisyllabic nouns. Behavior Research Methods, 43, 1100-1109. https://doi.org/10.3758/s13428-011-0117-5

Binder, J. R., Conant, L. L., Humphries, C. J., Fernandino, L., Simons, S. B., Aguilar, M., \& Desai, R. H. (2016). Toward a brain-based componential semantic representation. Cognitive Neuropsychology, 33, 130-174. https://doi.org/10.1080/02643294.2016.1147426
Bonin, P., Méot, A., Aubert, L., Malardier, N., Niedenthal, P., \& CapelleToczek, M.-C. (2003). Normes de concrétude, de valeur d'imagerie, de fréquence subjective et de valence émotionnelle pour 866 mots. L'année Psychologique, 103, 655-694.

Bonin, P., Méot, A., \& Bugaiska, A. (2018). Concreteness norms for 1, 659 French words: Relationships with other psycholinguistic variables and word recognition times. Behavior Research Methods. Advance online publication. https://doi.org/10.3758/s13428-0181014-y

Bonin, P., Méot, A., Ferrand, L., \& Bugaïska, A. (2015). Sensory experience ratings (SERs) for 1,659 French words: Relationships with other psycholinguistic variables and visual word recognition. Behavior Research Methods, 47, 813-825. https://doi.org/10.3758/ s13428-014-0503-x

Bradley, M. M., \& Lang, P. J. (1994). Measuring emotion: The selfassessment manikin and the semantic differential. Journal of Behavior Therapy and Experimental Psychiatry, 25, 49-59. https://doi.org/10.1016/0005-7916(94)90063-9

Bradley, M. M., \& Lang, P. J. (1999). Affective norms for English words (ANEW): Instruction manual and affective ratings. Gainesville, FL: Center for Research in Psychophysiology, University of Florida.

Davies, R., Barbón, A., \& Cuetos, F. (2013). Lexical and semantic age-ofacquisition effects on word naming in Spanish. Memory \& Cognition, 41, 297-311. https://doi.org/10.3758/s13421-012-02638

Díez-Álamo, A. M., Díez, E., Alonso, M. A., Vargas, C. A., \& Fernandez, A. (2017). Normative ratings for perceptual and motor attributes of 750 object concepts in Spanish. Behavior Research Methods. Advance online publication. https://doi.org/10.3758/s13428-0170970-y

Duchon, A., Perea, M., Sebastián-Gallés, N., Martí, A., \& Carreiras, M. (2013). EsPal: One-stop shopping for Spanish word properties. Behavior Research Methods, 45, 1246-1258. https://doi.org/10. 3758/s13428-013-0326-1

Ekman, P. (1993). Facial expression and emotion. American Psychologist, 48, 384-392. https://doi.org/10.1037/0003-066X.48. 4.384

Ekman, P. (1999). Facial expressions. In T. Dalgleish \& M. J. Power (Eds.), Handbook of cognition and emotion (pp. 301-320). New York, NY: Wiley.

Fernandez, A., Díez, E., \& Alonso, M. A. (2017). Normas de Asociación libre en castellano de la Universidad de Salamanca [online database]. Retrieved from campus.usal.es/gimc/nalc

Fernandez, A., Díez, E., Alonso, M. A., \& Beato, M. S. (2004). Freeassociation norms for the Spanish names of the Snodgrass and Vanderwart pictures. Behavior Research Methods, Instruments, \& Computers, 36, 577-583. https://doi.org/10.3758/BF03195604

Ferré, P., Guasch, M., Martínez-García, N., Fraga, I., \& Hinojosa, J. A. (2017). Moved by words: Affective ratings for a set of 2,266 Spanish words in five discrete emotion categories. Behavior Research Methods, 49, 1082-1094. https://doi.org/10.3758/ s13428-016-0768-3

Ferré, P., Guasch, M., Moldovan, C., \& Sánchez-Casas, R. (2012). Affective norms for 380 Spanish words belonging to three different semantic categories. Behavior Research Methods, 44, 395-403. https://doi.org/10.3758/s13428-011-0165-x

Glenberg, A. M. (2011). How reading comprehension is embodied and why that matters. International Electronic Journal of Elementary Education, 4, 5-18.

Glenberg, A. M. (2015). Few believe the world is flat: How embodiment is changing the scientific understanding of cognition. Canadian Journal of Experimental Psychology, 69, 165-171. https://doi.org/ $10.1037 / \mathrm{cep} 0000056$

Glenberg, A. M., \& Kaschak, M. P. (2002). Grounding language in action. Psychonomic Bulletin \& Review, 9, 558-565. https://doi.org/ 10.3758/BF03196313 
González-Nosti, M., Barbón, A., Rodríguez-Ferreiro, J., \& Cuetos, F. (2014). Effects of the psycholinguistic variables on the lexical decision task in Spanish: A study with 2,765 words. Behavior Research Methods, 46, 517-525. https://doi.org/10.3758/s13428-013-0383-5

Hallgren, K. A. (2012). Computing inter-rater reliability for observational data: An overview and tutorial. Tutorials in Quantitative Methods for Psychology, 8, 23-34. https://doi.org/10.20982/tqmp.08.1.p023

Hinojosa, J. A., Martínez-García, N., Villalba-García, C., FernándezFolgueiras, U., Sánchez-Carmona, A., Pozo, M. A., \& Montoro, P. R. (2016a). Affective norms of 875 Spanish words for five discrete emotional categories and two emotional dimensions. Behavior Research Methods, 48, 272-284. https://doi.org/10.3758/s13428015-0572-5

Hinojosa, J. A., Rincón-Pérez, I., Romero-Ferreiro, M. V., MartínezGarcía, N., Villalba-García, C., Montoro, P. R., \& Pozo, M. A. (2016b). The Madrid Affective Database for Spanish (MADS): Ratings of dominance, familiarity, subjective age of acquisition and sensory experience. PLOS ONE, 11, e0155866. https://doi.org/ 10.1371/journal.pone.0155866

Hirschfeld, G., Bien, H., de Vries, M., Lüttmann, H., \& Schwall, J. (2010). Open-source software to conduct online rating studies. Behavior Research Methods, 42, 542-546. https://doi.org/10.3758/ BRM.42.2.542

Juhasz, B. J., Lai, Y.-H., \& Woodcock, M. L. (2015). A database of 629 English compound words: Ratings of familiarity, lexeme meaning dominance, semantic transparency, age of acquisition, imageability, and sensory experience. Behavior Research Methods, 47, 10041019. https://doi.org/10.3758/s13428-014-0523-6

Juhasz, B. J., \& Yap, M. J. (2013). Sensory experience ratings for over 5, 000 mono- and disyllabic words. Behavior Research Methods, 45, 160-168. https://doi.org/10.3758/s13428-012-0242-9

Juhasz, B. J., Yap, M. J., Dicke, J., Taylor, S. C., \& Gullick, M. M. (2011). Tangible words are recognized faster: The grounding of meaning in sensory and perceptual systems. Quarterly Journal of Experimental Psychology, 64, 1683-1691. https://doi.org/10.1080/17470218. 2011.605150

Kaschak, M. P., Madden, C. J., Therriault, D. J., Yaxley, R. H., Aveyard, M., Blanchard, A. A., \& Zwaan, R. A. (2005). Perception of motion affects language processing. Cognition, 94, B79-B89. https://doi. org/10.1016/j.cognition.2004.06.005

Kensinger, E. A., \& Corkin, S. (2004). Two routes to emotional memory: Distinct neural processes for valence and arousal. Proceedings of the National Academy of Sciences, 101, 3310-3315. https://doi.org/10. 1073/pnas.0306408101

Kiefer, M., \& Barsalou, L. W. (2013). Grounding the human conceptual system in perception, action, and internal states. In W. Prinz, M. Beisert, \& A. Herwig (Eds.), Action science: Foundations of an emerging discipline (pp. 381-407). Cambridge, MA: MIT Press.

Kousta, S.-T., Vigliocco, G., Vinson, D. P., Andrews, M., \& Del Campo, E. (2011). The representation of abstract words: Why emotion matters. Journal of Experimental Psychology: General, 140, 14-34. https://doi.org/10.1037/a0021446

Kuperman, V. (2013). Accentuate the positive: Semantic access in English compounds. Frontiers in Psychology, 4, 203. https://doi. org/10.3389/fpsyg.2013.00203

Kuperman, V., Estes, Z., Brysbaert, M., \& Warriner, A. B. (2014). Emotion and language: Valence and arousal affect word recognition. Journal of Experimental Psychology: General, 143, 1065-1081. https://doi.org/10.1037/a0035669

Kwok, R. K. W., Cuetos, F., Avdyli, R., \& Ellis, A. W. (2017). Reading and lexicalization in opaque and transparent orthographies: Word naming and word learning in English and Spanish. Quarterly Journal of Experimental Psychology, 70, 2105-2129. https://doi. org/10.1080/17470218.2016.1223705

Lambon Ralph, M. A., Jefferies, E., Patterson, K., \& Rogers, T. T. (2017). The neural and computational bases of semantic cognition. Nature Reviews Neuroscience, 18, 42-55. https:// doi.org/10.1038/nrn.2016.150

Liu, Y., Shu, H., \& Li, P. (2007). Word naming and psycholinguistic norms: Chinese. Behavior Research Methods, 39, 192-198. https://doi.org/10.3758/BF03193147

Lynott, D., \& Connell, L. (2013). Modality exclusivity norms for 400 nouns: The relationship between perceptual experience and surface word form. Behavior Research Methods, 45, 516-526. https://doi. org/10.3758/s13428-012-0267-0

McRae, K., Cree, G. S., Seidenberg, M. S., \& McNorgan, C. (2005). Semantic feature production norms for a large set of living and nonliving things. Behavior Research Methods, 37, 547-559. https://doi.org/10.3758/BF03192726

Medler, D. A., Arnoldussen, A., Binder, J. R., \& Seidenberg, M. S. (2005). The wisconsin perceptual attribute ratings database. Retrieved from www.neuro.mcw.edu/ratings/

Mirman, D., \& Magnuson, J. S. (2006). The impact of semantic neighborhood density on semantic access. In R. Sun \& N. Miyake (Eds.), Proceedings of the 28th Annual Conference of the Cognitive Science Society (pp. 1823-1828). Mahwah, NJ: Erlbaum.

Oatley, K., \& Johnson-Laird, P. N. (1987). Towards a cognitive theory of emotions. Cognition and Emotion, 1, 29-50. https://doi.org/10. 1080/02699938708408362

Pérez, M. A., Campoy, G., \& Navalón, C. (2001). Índice de estudios normativos en idioma español. Revista Electrónica de Metodología Aplicada, 6, 85-105.

Power, M., \& Dalgleish, T. (1997). Cognition and emotion: From order to disorder. Hove, UK: Psychology Press.

Proctor, R. W., \& Vu, K.-P. L. (1999). Index of norms and ratings published in the Psychonomic Society journals. Behavior Research Methods, Instruments, \& Computers, 31, 659-667. https://doi.org/ 10.3758/BF03200742

Redondo, J., Fraga, I., Comesaña, M., \& Perea, M. (2005). Estudio normativo del valor afectivo de 478 palabras españolas. Psicológica, 26, 317-326.

Redondo, J., Fraga, I., Padrón, I., \& Comesaña, M. (2007). The Spanish adaptation of ANEW (Affective Norms for English Words). Behavior Research Methods, 39, 600-605. https://doi.org/10.3758/ BF03193031

Sanfeliu, M. C., \& Fernandez, A. (1996). A set of 254 SnodgrassVanderwart pictures standardized for Spanish: Norms for name agreement, image agreement, familiarity, and visual complexity. Behavior Research Methods, Instruments, \& Computers, 28, 537555. https://doi.org/10.3758/BF03200541

Snodgrass, J. G., \& Vanderwart, M. (1980). A standardized set of 260 pictures: Norms for name agreement, image agreement, familiarity, and visual complexity. Journal of Experimental Psychology: Human Learning and Memory, 6, 174-215. https://doi.org/10. 1037/0278-7393.6.2.174

Stadthagen-González, H., Ferré, P., Pérez-Sánchez, M. A., Imbault, C., \& Hinojosa, J. A. (2017a). Norms for 10,491 Spanish words for five discrete emotions: Happiness, disgust, anger, fear, and sadness. Behavior Research Methods. https://doi.org/10.3758/s13428-0170962-y

Stadthagen-González, H., Imbault, C., Pérez Sánchez, M. A., \& Brysbaert, M. (2017b). Norms of valence and arousal for 14,031 Spanish words. Behavior Research Methods, 49, 111-123. https:// doi.org/10.3758/s13428-015-0700-2

Thill, S., \& Twomey, K. E. (2016). What's on the inside counts: A grounded account of concept acquisition and development. Frontiers in Psychology, 7, 402. https://doi.org/10.3389/fpsyg. 2016.00402

Tillotson, S. M., Siakaluk, P. D., \& Pexman, P. M. (2008). Body-object interaction ratings for 1,618 monosyllabic nouns. Behavior Research Methods, 40, 1075-1078. https://doi.org/10.3758/BRM. 40.4.1075 
Umla-Runge, K., Zimmer, H. D., Fu, X., \& Wang, L. (2012). An action video clip database rated for familiarity in China and Germany. Behavior Research Methods, 44, 946-953. https://doi.org/10.3758/ s13428-012-0189-x

Vaughan, J. (2004). Editorial: A Web-based archive of norms, stimuli, and data. Behavior Research Methods, Instruments, \& Computers, 36, 363-370. https://doi.org/10.3758/BF03195583

Warriner, A. B., Kuperman, V., \& Brysbaert, M. (2013). Norms of valence, arousal, and dominance for 13,915 English lemmas. Behavior
Research Methods, 45, 1191-1207. https://doi.org/10.3758/s13428012-0314-x

Yoon, C., Feinberg, F., Luo, T., Hedden, T., Gutchess, A. H., Chen, H.-Y. M., ... Park, D. C. (2004). A cross-culturally standardized set of pictures for younger and older adults: American and Chinese norms for name agreement, concept agreement, and familiarity. Behavior Research Methods, Instruments, \& Computers, 36, 639-649. https:// doi.org/10.3758/BF03206545 